\title{
Tackling ethnic variations in asthma outcomes in New Zealand's Mãori and Pacific children will need a long-term strategy
}

\author{
Emma Davidson', *Aziz Sheikh² \\ 1 Research Fellow, Allergy \& Respiratory Research Group, Centre \\ for Population Health Sciences, The University of Edinburgh, \\ Edinburgh, UK \\ 2 Professor of Primary Care Research \& Development and Co- \\ Director, Allergy \& Respiratory Research Group, Centre for \\ Population Health Sciences, The University of Edinburgh, \\ Edinburgh, UK; and Harkness Fellow in Health Care Policy and \\ Practice, Division of General Internal Medicine and Primary Care, \\ Brigham and Women's Hospital/Harvard Medical School, Boston, \\ Massachusetts, USA
}

*Correspondence: Professor Aziz Sheikh, Centre for Population Health Sciences, Teviot Place, Edinburgh EH8 9AG, UK Tel: +44 (0)131650 8102 Fax: +44 (0)131 6509119 E-mail: aziz.sheikh@ed.ac.uk

\section{See linked article by Gillies et al. on pg 312}

Societies globally are becoming increasingly ethnically diverse and this is a trend that is set to continue for the foreseeable future. Ensuring comparability in service delivery and outcomes for different sectors of the population is an issue that is of increasing interest to policymakers, particularly in relation to long-term conditions such as asthma - this being motivated by a combination of wishes to address past wrongs, promote fairness and social cohesion, and to reduce health costs.

However, it has proved surprisingly difficult to address these inequalities and to improve health outcomes in disadvantaged minority ethnic populations. For example, our systematic review of UK data found that, despite years of policy initiatives aiming to improve care provision to minority groups, people of South Asian origin had a three-fold increased risk of hospital admission for asthma and in people of Black origin the risk of admission for asthma was doubled when compared with the majority White population. ${ }^{1}$ Similar racial and ethnic disparities in asthma outcomes have also been noted in the USA, and for indigenous populations worldwide. ${ }^{2}$

The reasons underlying these ethnic disparities and why they persist remain poorly understood. The paper by Gillies et al. ${ }^{3}$ in this issue of the $P C R J$ is welcome in that it moves beyond describing ethnic variations to understanding the underlying factors that may be responsible for driving these inequalities in a New Zealand context. Studying these issues is particularly important in New Zealand because of the very high prevalence of asthma and because the major ethnic minority groups - namely Mãori and Pacific peoples - are known to experience asthma inequalities when compared to the majority White European-origin population. This work is also interesting because although Mãori and Pacific peoples share similar asthma-related disadvantage, they have very different social, cultural and political histories, which therefore offers the opportunity to tease out potentially wider, internationally transferable lessons.

Mãori are tangata whenua (indigenous people) and comprise around $15 \%$ of the population. Fundamental to understanding the health status of Mãori is recognising their experience of colonisation which has marginalised Mãori, creating long-standing unequal power dynamics affecting their social, economic, political and cultural position. ${ }^{4,5}$ Inequalities in health between Mãori and non-Mãori in New Zealand have been described as "consistent and compelling", with disparities identified both in relation to deprivation and independently, once deprivation has been controlled. ${ }^{6}$

In contrast, people from the Pacific Islands of Samoa, Cook Islands, Tonga, Niue, Fiji, Tokelau and Tuvalu make up approximately $7 \%$ of New Zealand's population. This group represents a diverse range of people with distinct languages, heritages, and national origins. Overall, about $40 \%$ are first-generation migrants from the Pacific Islands (ranging from $37 \%$ of Tuvaluans to $74 \%$ of Nueians). However, unlike some migrant populations who demonstrate a healthy migrant effect, New Zealand's Pacific population appears to come with a health disadvantage, which persists after migration. ${ }^{7}$

Gilles and colleagues explored ethnic disparities by examining asthma treatment and outcomes in all children less than 15 years of age in New Zealand. ${ }^{3}$ Their main hypotheses were to investigate if the known asthma inequalities were due to less optimal treatment and lower adherence to guidelines in the context of delivering care to Mãori and Pacific children. Their major findings were that Mãori and Pacific children were more likely to be hospitalised than their European-origin peers, and that this may, at least in part, be explained by sup-optimal treatment (as evidenced by the fact that Mãori and Pacific remained on the lowest step of asthma treatment) and that, irrespective of disease severity, they had the highest use of rescue oral steroids.

This work provides a unique contribution as the first study to sample from a whole population cohort of New Zealand children as opposed to more regional studies. ${ }^{8}$ The paper also adds to the field by unravelling some of the underlying mechanisms of these inequalities. New Zealand's health system is part subsidised with free hospital care for all and free primary care consultations for those less than six years of age. Gillies et al.'s data showed that older Mãori and Pacific children were less likely to receive appropriate treatment than those aged less than 5 years. In addition, rescue oral steroid use and hospital admissions were higher in older Mãori and Pacific Island children, as were unplanned hospital admissions for children not previously treated for asthma before admission. These findings therefore suggest that access to appropriate primary care treatment is constrained by cost considerations for Mãori and Pacific populations and that this may in part explain the poor outcomes.

This is, however, unlikely to explain the full picture, as evidenced by the poor outcomes also noted in those aged under six in whom 
care provision is free of charge. The authors therefore helpfully broaden the discussion to consider cultural issues, including the contribution of differing health beliefs and communication challenges to understanding treatment and adherence-related considerations. Addressing these cultural factors has been highlighted as being pivotal to improving asthma outcomes for Mãori. ${ }^{9}$ It has been suggested that partnership approaches to health services, ${ }^{10,11}$ the use of indigenous healthcare workers, $^{12}$ and the creation of culturally adapted educational resources, ${ }^{13}$ may be beneficial in improving asthma outcomes and providing broader health benefits.

Given the persistent and complex nature of these inequalities, Gilles et al. are right to conclude that Mãori and Pacific children warrant special attention in policy making and health service planning. To this one may add that this focus on these populations needs to be maintained, with progress being regularly monitored over time. The excellent linked dataset infrastructure available in New Zealand is clearly a major asset in this respect. Whilst this all seems reasonable, the main policy challenge comes from the fact that a recent scoping study of the cost of child health inequalities in New Zealand suggests that maintaining existing inequities may actually be a cheaper option in the short-term for the health sector when compared to actually addressing these inequalities, which would require substantial investment. ${ }^{4}$

The core underlying issue, therefore, is that redressing a system where healthcare spending is skewed towards the majority population ${ }^{4}$ is likely to prove challenging, despite the fact that eliminating disparities is consistent with indigenous rights, ${ }_{1}^{5}$ Ministry of Health goals, ${ }^{9,14}$ and is likely to lead to larger societal gains in the longer-term. ${ }^{4}$ This is a challenge that faces New Zealand's policymakers and indeed health service planners globally. ${ }^{15}$

Conflicts of interest ED has no conflicts of interests to declare. AS is Joint Editor-in-Chief of the $P C R J$, but was not involved in the editorial review of, nor the decision to publish, this article.

Funding AS is supported by The Commonwealth Fund, a private independent foundation based in New York City. The views presented here are those of the author and not necessarily those of The Commonwealth Fund, its directors, officers, or staff.

Commissioned article; not externally peer-reviewed; accepted 7th August 2013; online 18th August 2013

(C) 2013 Primary Care Respiratory Society UK. All rights reserved

http://dx.doi.org/10.4104/pcrj.2013.00076

Prim Care Respir J 2013; 22(3): 269-270

\section{References}

1. Netuveli G, Hurwitz B, Levy M, et al. Ethnic variations in UK asthma frequency, morbidity, and health-service use: a systematic review and meta-analysis. Lancet 2005;365:312-17.

2. Ospina MB, Voaklander DC, Stickland MC, King M, Senthilselvan A, Rowe BH Prevalence of asthma and chronic obstructive pulmonary disease in Aboriginal and non-Aboriginal populations: a systematic review and meta-analysis of epidemiological studies. Canad Resp J 2012;19:355-60.

3. Gillies TD, Tomlin AM, Dovey SM, Tilyard MW. Ethnic disparities in asthma treatment and outcomes in children aged under 15 years in New Zealand: analysis of national databases. Prim Care Respir J 2013;22(3):312-18. http://dx.doi.org/10.4104/pcrj.2013.00068

4. Mills $C$, Reid $P$, Vaithianathan R. The cost of child health inequalities in Aotearoa New Zealand: a preliminary scoping study. BMC Pub HIth 2012;12:384. http://dx.doi.org/10.1186/1471-2458-12-384

5. Robson B, Harris R. (eds). Hauora: Mãori Standards of Health IV. A study of the years 2000-2005. Wellington: Te Ropu Rangahau Hauora a Eru Pomare, 2007:3.

6. Reid P, Robson B, Jones CP. Disparities in health: common myths and uncommon truths. Pacific Hith Dialog 2000;7:38-47.

7. Hajat A, Blakely T, Dayal S, Jatrana S. Do New Zealand's immigrants have a mortality advantage? Evidence from the New Zealand Census-Mortality Study. Ethn Health 2010;15:531-47

8. Crengle S, Robinson E, Grant C, Arroll B. Pharmocological management of children's asthma in general practice: findings from a community-based crosssectional survey in Auckland, New Zealand. NZ Med J 2011;124:44-56.

9. Ellison-Loschmann L, Pearce N. He Mate Huango: an update on Maori asthma. Pacific HIth Dialog 2000;7:82-93.

10. Ratima MM, Fox C, Fox B, et al. Long-term benefits for Maori of an asthma selfmanagement program in a Maori community which takes a partnership approach. Aust NZ J Public Health 1999;23:601-05. http://dx.doi.org/10.1111/j.1467-842X.1999.tb01544.x

11. Jones $B$, Ingham TR, Cram F, Dean S, Davies C. An indigenous approach to explore health-related experiences among Maori parents: the Pukapuka Hauora asthma study. BMC Pub H/th 2013;13:228.http://dx.doi.org/10.1186/1471-2458-13-228

12. Chang $A B$, Taylor $B$, Masters $I B$, Laifoo $Y$, Brown ADH. Indigenous healthcare worker involvement for indigenous adults and children with asthma. Cochrane Datab Syst Rev 2010; 5.

13. Kristiansen J, Hetutu E, Manukia M, Jelleyman T. An evaluation of a pictorial asthma medication plan for Pacific children. NZ Med J 2012;125:42-50.

14. Ministry of Health: Reducing Inequalities in Health. Wellington: Ministry of Health, 2002.

15. Davidson E, Liu JJ, Sheikh A. The impact of ethnicity on asthma care. Prim Care Respir J 2010;19:202-08. http://dx.doi.org/10.4104/pcrj.2010.00013

\section{Available online at http://www.thepcrj.org}

